\title{
The subduction dichotomy of strong plates and weak slabs
}

\author{
Robert I. Petersen ${ }^{1}$, Dave R. Stegman ${ }^{1}$, and Paul J. Tackley ${ }^{2}$ \\ ${ }^{1}$ Institute of Geophysics and Planetary Physics, University of California, San Diego, 9500 Gilman Drive, \\ La Jolla, San Diego, CA 92093-0225, USA \\ ${ }^{2}$ Institute für Geophysik, ETH Zürich, Sonneggstrasse 5, 8092 Zürich, Switzerland \\ Correspondence to: Robert I. Petersen (rpetersen@ucsd.edu)
}

Received: 25 March 2016 - Discussion started: 5 April 2016

Revised: 14 July 2016 - Accepted: 21 July 2016 - Published: 24 March 2017

\begin{abstract}
A key element of plate tectonics on Earth is that the lithosphere is subducting into the mantle. Subduction results from forces that bend and pull the lithosphere into the interior of the Earth. Once subducted, lithospheric slabs are further modified by dynamic forces in the mantle, and their sinking is inhibited by the increase in viscosity of the lower mantle. These forces are resisted by the material strength of the lithosphere. Using geodynamic models, we investigate several subduction models, wherein we control material strength by setting a maximum viscosity for the surface plates and the subducted slabs independently. We find that models characterized by a dichotomy of lithosphere strengths produce a spectrum of results that are comparable to interpretations of observations of subduction on Earth. These models have strong lithospheric plates at the surface, which promotes Earth-like single-sided subduction. At the same time, these models have weakened lithospheric subducted slabs which can more easily bend to either lie flat or fold into a slab pile atop the lower mantle, reproducing the spectrum of slab morphologies that have been interpreted from images of seismic tomography.
\end{abstract}

\section{Introduction}

A key element of plate tectonics is the recycling of lithospheric plates into the mantle. Colder and more dense slabs, already having been subducted, generate the driving force that pulls and bends tectonic plates below the surface. Coupling of tectonic plates at the surface, shear stress on the subducted plate, induction of mantle flow around the subducting plate, the contact of slabs with upper mantle/lower mantle boundary, and the material strength of plates generate resisting forces which resist bending inhibit subduction. The particular form and speed of subduction is controlled by the balance of the opposing forces (Jarrard, 1986; Royden and Husson, 2009; Petersen et al., 2015).

On Earth this process is asymmetric, occurring at convergent boundaries where one of the two plates is subducted, while the other plate, the overriding plate, remains at the surface. The mechanical strength of lithospheric material needs to be sufficiently strong so that the overriding plate can resist bending while being weak enough so that the subducting plate can bend and subduct.

Subducted slabs moving through the mantle and encountering the higher viscosity lower mantle experience forces that deform the slab. These forces are transmitted to the surface, the slab acting as a stress guide, affecting the state of stress at the trench and the coupling of subducting and overriding plates (Clark et al., 2008).

Models produce a diverse set of mantle convection styles (Solomatov and Moresi, 1997; Crameri et al., 2012b; Gerya et al., 2008; O'Neill, 2012; Lenardic and Crowley, 2012; O'Rourke and Korenaga, 2012), including stagnant lid, twosided downwellings, and one-sided subduction. Our geodynamic models use the rheological laws of viscoplastic, temperature-dependent material to provide a laboratory for examining subduction systems. By introducing a temperature and depth dependency on the maximum viscosity allowable, we are able to investigate subduction where the cold material of subducted slab is weaker than the surface plate. We can address questions regarding the resistance of surface plates to bending and the morphology of subducted slabs in the upper mantle. Our models allow for contrasting viscosity at depth, enabling us to look at how the presence or absence of a higher viscosity lower mantle affects the system. 
Table 1. Parameters common to all models.

\begin{tabular}{lll}
\hline Parameter & Description & Value \\
\hline$x$ & Domain width & $5440 \mathrm{~km}$ \\
$z$ & Domain depth & $1360 \mathrm{~km}$ \\
$n x$ & Horizontal cells & 1024 \\
$n z$ & Vertical cells & 256 \\
$g$ & Gravitational acceleration & $9.81 \mathrm{~m} \mathrm{~s}^{-2}$ \\
$\rho_{0}$ & Reference density & $3300 \mathrm{~kg} \mathrm{~m}^{-3}$ \\
$C_{\mathrm{p}}$ & Heat capacity at constant pressure & $1200.0 \mathrm{~J} \mathrm{~K}^{-1}$ \\
$k$ & Thermal conductivity & $3 \mathrm{~W} \mathrm{~m}^{-1} \mathrm{~K}^{-1}$ \\
$\eta_{\text {ref }}$ & Reference viscosity at $T=1600 \mathrm{~K}$ & $1 \times 10^{20} \mathrm{~Pa} \mathrm{~s}$ \\
$\eta_{\text {air }}$ & Viscosity of "sticky air" & $1 \times 10^{18} \mathrm{~Pa} \mathrm{~s}$ \\
$h_{\text {air }}$ & Air layer thickness & $100 \mathrm{~km}$ \\
$h_{\text {weak crust }}$ & Weak crustal layer thickness & $8 \mathrm{~km}$ \\
$C_{\text {mantle }}$ & Mantle cohesion & $150.0 \mathrm{MPa}$ \\
$\mu_{\text {mantle }}$ & Mantle coefficient of friction & 0.1 \\
$C_{\text {weak crust }}$ & Weak crust cohesion & $1.0 \mathrm{MPa}$ \\
$\mu_{\text {weak crust }}$ & Weak crust coefficient of friction & 0.0 \\
\hline & & \\
\hline
\end{tabular}

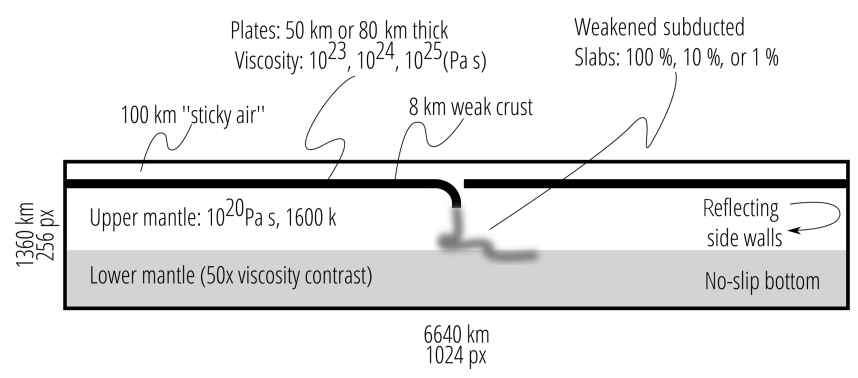

Figure 1. Diagram of the common parameter space, initial, and boundary conditions for models.

\section{Methods}

We develop two-dimensional models of convective systems using the finite volume code StagYY (Tackley, 2008). StagYY is a numerical model of solid-state mantle convection that solves the conservation equations for energy, momentum, and mass. The models use an incompressible material with an infinite Prandtl number approximation.

Dimensional parameters are used, and parameters common to all models are given in Table 1. A schematic of the model setup is shown in Fig. 1. The aspect ratio for all models is 4 to 1 , with a dimensional length of $5440 \mathrm{~km}$ and a depth of $1360 \mathrm{~km}$. In this study we examine models both with and without a lower mantle. For models with a lower mantle, the domain is divided into upper and lower portions with a size of 660 and $600 \mathrm{~km}$ respectively. The viscosity of the lower mantle is 50 times that of the upper mantle. A $100 \mathrm{~km}$ layer of "sticky air" (Schmeling et al., 2008; Crameri et al., 2012a, b) is placed at the top of the model. The model space is gridded using a grid of $1024 \times 256$ grid points, with vertical refinement around the air/rock interface. The minimum vertical resolution is $1.5 \mathrm{~km}$ and the maximum is $5.9 \mathrm{~km}$.

\subsection{Rheology}

We use a strongly temperature-dependent Arrhenius relation to calculate the viscosity of a silicate mantle, shown in Eq. (1).

$\eta(T)=A e^{\frac{E}{R T}}$,

where $\eta(T)$ is the temperature-dependent viscosity, $R$ is the gas constant, $T$ is temperature, and $E$ is the activation energy $\left(240 \mathrm{~kJ} \mathrm{~mol}^{-1}\right)$. The prefactor $A$ is calculated so that a reference mantle temperature of $T_{0}=1600 \mathrm{~K}$ results in a reference viscosity $\eta_{\text {ref }}=1 \times 10^{20} \mathrm{Pas}$. If the temperaturedetermined viscosity falls outside a specified window, a cutoff is applied. In this study, the maximum allowed viscosity, $\eta_{\max }$, is one of $10^{23}, 10^{24}$, or $10^{25} \mathrm{Pas}$, and the minimum viscosity of non-air material is $\eta_{\min }=10^{19} \mathrm{~Pa}$.

Material is subject to failure through an applied yield

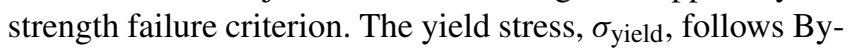
erlee's law and is pressure-dependent for the mantle:

$\sigma_{\text {yield }}=C+p \mu$,

where $C$ is the cohesion, $\mu$ is the coefficient of friction, and $p$ is the hydrostatic pressure. For the bulk of the mantle, $C=150.0 \mathrm{MPa}$ and $\mu=0.1$. For the weak crust layer, $C=1.0 \mathrm{MPa}$ and $\mu=0.0$.

Weakening of the subducted slab is accomplished by lowering the maximum viscosity at depth for material below $1000 \mathrm{~K}$. In the models where slab weakening is used, material $10 \mathrm{~km}$ below the depth of the lithosphere/asthenosphere boundary is assigned a lower maximum viscosity than the surface plates. We use plates of 50 and $80 \mathrm{~km}$ in this study, and the weakening is applied to material below 60 and $90 \mathrm{~km}$ respectively. We examine cases where the weakening is 1 , 10 , or $100 \%$ (no weakening) of the maximum viscosity cutoff of the surface plates. In a study by Garel et al. (2014), the authors developed models which used a composite viscosity calculated as the harmonic mean of several rheological laws, Peierls and non-Newtonian flow among them. In that study, the authors find the primary deformation mechanism of Peierls creep to be widely active inside the slab, beginning around the depth of the base of the overriding plate to depths of $660 \mathrm{~km}$. Further, they show dislocation creep to be the primary deformation mechanism within the slab at the edges, while there continues to be an overall viscosity contrast between slab and background mantle. The range of depths where weakening is effective corresponds to those where Garel et al. (2014) found that Peierls and dislocation creep are the dominant deformation mechanisms. The starting depth for the weakening is at a point where the subducting plate has been bent and is below the interface between the subducting and overriding plate. In the models of this study, the depth is below where the yield criteria are activated in the bending region of the plate. In viscoplastic models of mantle 


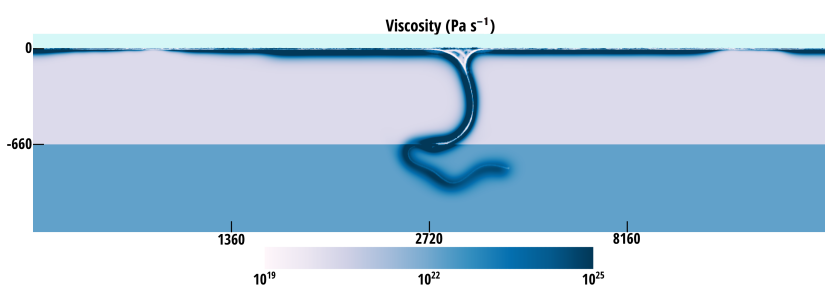

Figure 2. Piled slab descending into the lower mantle.

convection, where stresses exceed the yield criteria, the effective viscosity is decreased until the maximum stresses allowed are achieved. However, with the usual implementation of viscoplasticity, the lithosphere has no memory of having yielded or undergone large deformation while in the bending region. Upon leaving the bending region and the associated high stresses, its mechanical strength is instantaneously recovered to follow the same rheological description it was assigned prior to being subducted. Here we explore an alternative view that material strength might not be instantaneously restored to its full pre-yielded value and acknowledge that the geological material may have been weakened as a result. We use a computationally efficient way of parameterizing the effective viscosity that may result due to any number of mechanisms that may be active subsequent to leaving the high stress bending region, including the development of weakened tectonic fabrics or subgrid faults in the lithosphere, in addition to the possible activation of Peierls creep, damage rheology, or other non-Newtonian rheologies (Kameyama et al., 1999; Bercovici, 2003; Garel et al., 2014; Bercovici et al., 2015; Holt et al., 2015a).

\subsection{Initial condition}

A temperature field and particle cloud are the initial conditions for all models. The temperature field is defined by a uniform background temperature of $1600 \mathrm{~K}$ and plates with a half-space cooling temperature gradient. The viscosity of the background and plates is calculated using Eq. (1), subject to cutoffs.

The surface of each model is comprised of two plates. The initial downgoing plate begins $20 \mathrm{~km}$ from the left wall. It extends to the center of the box (the initial trench) and then follows a path with radius of curvature $400 \mathrm{~km}$ at the surface of the slab into the mantle to a depth of $200 \mathrm{~km}$.

The overriding plate occupies the right side of the box, from $20 \mathrm{~km}$ right of the trench to $200 \mathrm{~km}$ short of the right wall. The boundary conditions reflect along the sides of the model domain, free slip at the top and no slip along the bottom.

\subsection{The surface}

These models use a pseudo-free surface in the form of a low density layer at the top of the model called sticky air
(Schmeling et al., 2008). The viscosity of the air is $10^{18} \mathrm{~Pa}$, 10 times lower than the minimum allowed viscosity of the mantle material.

To promote one-sided subduction (Crameri et al., 2012b), the top $8 \mathrm{~km}$ of the mantle material is a layer of weak crust, which has a lower yield strength as described above. The material accommodates the plastic deformation of the bending plate (Capitanio et al., 2009).

\subsection{Radius of curvature}

Radius of curvature has been used in several studies as a metric of subduction (Becker et al., 1999; Conrad and Hager, 1999; Buffett and Heuret, 2011; Holt et al., 2015b). In this study we first examine three methods for calculating the radius of curvature. All methods use tracer particles that represent the crust of the subducted slab.

The "spline" method has been used previously in studies to calculate a minimum radius of curvature for subducting slabs in both numerical models and in the Earth (Buffett and Heuret, 2011; Holt et al., 2015b). This method fits a smooth cubic spline to points, or observed locations of earthquake hypocenters (Buffett and Heuret, 2011), with a penalty on the second derivative (De Boor, 1978). The size of penalty is controlled by a weighting parameter between 0 and 1 . When the parameter is 0 , the method returns a least square straight line fit to the data. When it is 1 , the method returns a piecewise cubic spline passing through the data. As input we use crustal particles along the subducted slab from the trench to the $150 \mathrm{~km}$ depth.

In a second method, which we call the "angle" method, we first fit a curve to the base of the crust. We then select crust particles from the trench to the point where that curve has a slope of -1 . Using a least squares fit we fit a circle to the crustal particles. The third method, the "depth" method, fits a circle, as in the angle method, using crustal particles from the trench to a depth of $150 \mathrm{~km}$.

\section{Results}

\subsection{Model evolution}

We ran 36 models, varying the plate strength and weakening parameter of slabs (full list of parameters in Table 2). The evolution of all models is comparable in terms of their general behavior and slab morphology. All models begin with the slab tip sinking and the radius of curvature adjusting from the initial condition towards a dynamic equilibrium.

For models with a lower mantle, the slab descends through the upper mantle and encounters the boundary between the upper and lower mantle. The descent of the slab is inhibited at this boundary. Lateral motion of the slab tip is also inhibited, either because the tip penetrates into the lower mantle, or because the slab rests on the boundary and is subject to shear traction between the slab and lower mantle. The 
Table 2. Model parameters.

\begin{tabular}{|c|c|c|c|c|}
\hline Model no. & $\begin{array}{c}\text { Max. } \\
\text { viscosity (Pa s) }\end{array}$ & $\begin{array}{c}\text { Lithosphere } \\
\text { thickness }(\mathrm{km})\end{array}$ & $\begin{array}{c}\text { Slab strength } \\
(\% \text { of max. viscosity) }\end{array}$ & $\begin{array}{l}\text { Lower/upper } \\
\text { mantle contrast }\end{array}$ \\
\hline 1 & $10^{23}$ & 50 & 1 & 50 \\
\hline 2 & $10^{23}$ & 50 & 10 & 50 \\
\hline 3 & $10^{23}$ & 50 & 100 & 50 \\
\hline 4 & $10^{24}$ & 50 & 1 & 50 \\
\hline 5 & $10^{24}$ & 50 & 10 & 50 \\
\hline 6 & $10^{24}$ & 50 & 100 & 50 \\
\hline 7 & $10^{25}$ & 50 & 1 & 50 \\
\hline 8 & $10^{25}$ & 50 & 10 & 50 \\
\hline 9 & $10^{25}$ & 50 & 100 & 50 \\
\hline 10 & $10^{23}$ & 80 & 1 & 50 \\
\hline 11 & $10^{23}$ & 80 & 10 & 50 \\
\hline 12 & $10^{23}$ & 80 & 100 & 50 \\
\hline 13 & $10^{24}$ & 80 & 1 & 50 \\
\hline 14 & $10^{24}$ & 80 & 10 & 50 \\
\hline 15 & $10^{24}$ & 80 & 100 & 50 \\
\hline 16 & $10^{25}$ & 80 & 1 & 50 \\
\hline 17 & $10^{25}$ & 80 & 10 & 50 \\
\hline 18 & $10^{25}$ & 80 & 100 & 50 \\
\hline 19 & $10^{23}$ & 50 & 1 & 1 \\
\hline 20 & $10^{23}$ & 50 & 10 & 1 \\
\hline 21 & $10^{23}$ & 50 & 100 & 1 \\
\hline 22 & $10^{24}$ & 50 & 1 & 1 \\
\hline 23 & $10^{24}$ & 50 & 10 & 1 \\
\hline 24 & $10^{24}$ & 50 & 100 & 1 \\
\hline 25 & $10^{25}$ & 50 & 1 & 1 \\
\hline 26 & $10^{25}$ & 50 & 10 & 1 \\
\hline 27 & $10^{25}$ & 50 & 100 & 1 \\
\hline 28 & $10^{23}$ & 80 & 1 & 1 \\
\hline 29 & $10^{23}$ & 80 & 10 & 1 \\
\hline 30 & $10^{23}$ & 80 & 100 & 1 \\
\hline 31 & $10^{24}$ & 80 & 1 & 1 \\
\hline 32 & $10^{24}$ & 80 & 10 & 1 \\
\hline 33 & $10^{24}$ & 80 & 100 & 1 \\
\hline 34 & $10^{25}$ & 80 & 1 & 1 \\
\hline 35 & $10^{25}$ & 80 & 10 & 1 \\
\hline 36 & $10^{25}$ & 80 & 100 & 1 \\
\hline
\end{tabular}

slab then lies flat on the upper/lower mantle boundary, after which it buckles and piles. Eventually the piled slab descends through the boundary as a unit; see Fig. 2 .

For models with no lower mantle, the slab descends until it encounters the bottom of the model box. The bottom has a no-slip boundary condition. When the slab encounters the bottom of the box, it lies down and buckles in a manner similar to those models with a lower mantle in which the slab becomes embedded.

\subsection{Radius of curvature}

We calculated the radius of curvature for every time step and every model using the three methods described above. The initial condition imposed a radius of curvature of $400 \mathrm{~km}$. In the 0th time step, no method returned $400 \mathrm{~km}$. The fact that no method returns exactly the prescribed radius of curvature is a result of three factors: first, the $400 \mathrm{~km}$ radius of curvature used in the initial condition is at the surface of the plate, while the fit circles are mid-crust; second, the least squares fit to a cloud of randomly placed points is a statistical solution subject to noise; third, and most significant, no method selects all of the points from the trench to the tip of the slab. 


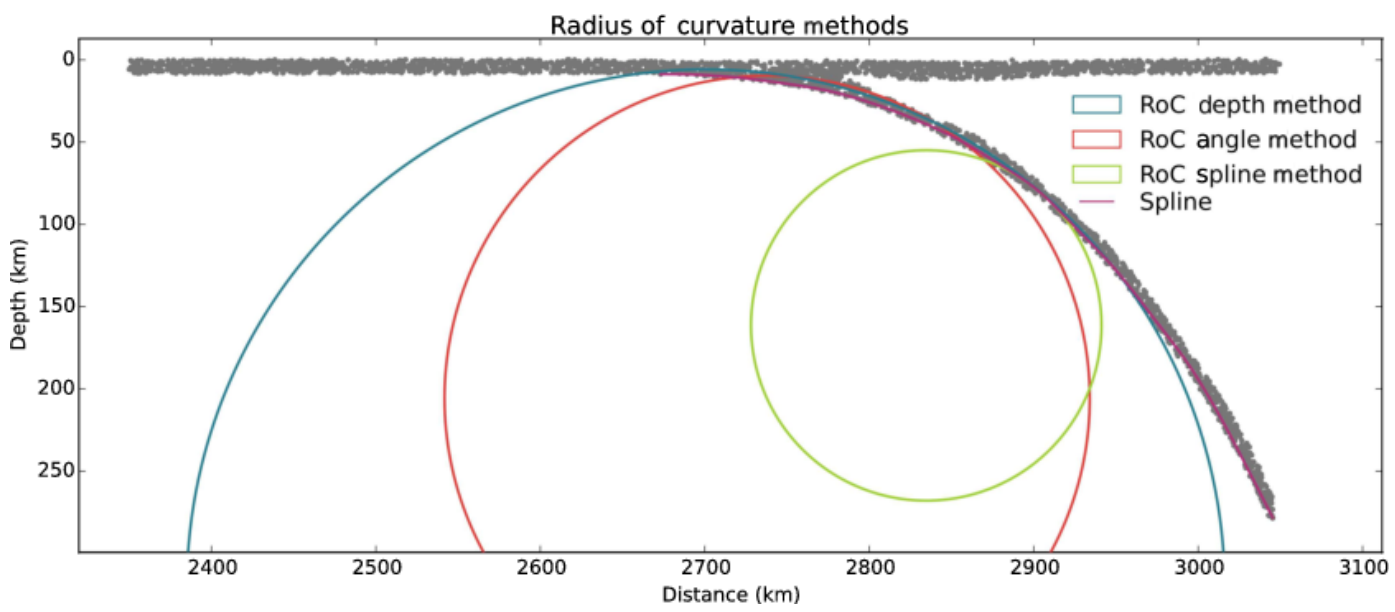

Figure 3. A comparison of the radius of curvature (RoC) calculated for each of the methods tested for model 14.

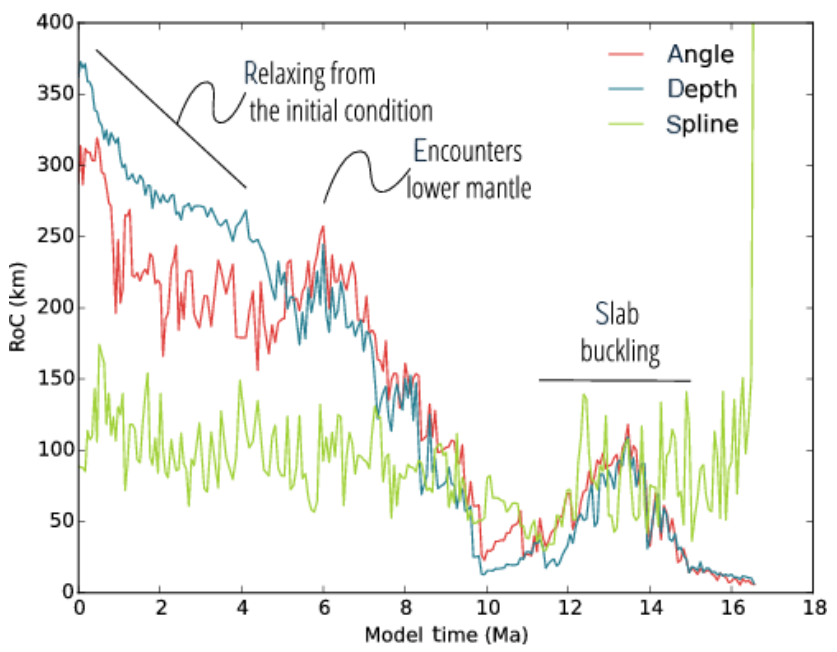

Figure 4. Radius of curvature over time for each method tested for model 14.

This angle method, in the case of a perfect circle, will select points down to a depth of $117 \mathrm{~km}$. The depth method is prescribed to select points no deeper than $150 \mathrm{~km}$. The spline method is also a statistical method, subject to an arbitrary smoothing parameter, and the radius of curvature at any given point is only sensitive to nearby particles. The depth method always returned the closest radius of curvature. The average across models for the 0th time step for depth, angle, and spline methods was 370,337 , and $113 \mathrm{~km}$, respectively.

The three methods of calculating the radius of curvature for subducted slabs return differing values for any given time step in the model. Figure 3 shows the results for a representative model (14), at a single time step. The figure shows the crustal particles, downsampled to enhance visibility, in gray. For each of the least squares circle fit methods, angle (red) and depth (blue), the calculated circle is plotted using the center point and radius returned by the method. The smoothed spline (magenta) is shown on top of the slab particle dots. The green circle shows the minimum radius of curvature given by the spline method. The circle is plotted to be tangent to the spline at the point of minimum radius of curvature and with the appropriate radius. Figure 4 shows the radius of curvature calculations for the same model over time. For each of the three methods, the relative size of the resultant radii of curvature changes during the model run. The first movement of the slabs is due to the slabs relaxing from the initial state and is characterized by a decrease in radii of curvature. The radii of curvature continue to decrease as the slabs descend through the upper mantle. During the initial period of relaxation from the initial condition, the depth method calculates a larger radius of curvature than the angle method, which is larger still than the spline method. Upon encountering the lower mantle, both "circle" methods calculate a similar radius of curvature and increase the rate of radius of curvature reduction. The spline method returns roughly equivalent values during the relaxation period and during the period in which the slab encounters the lower mantle. The minimum radius of curvature returned by all methods happens during the period when the slab is resting on the upper mantle. During the phase of buckling and piling, the radius of curvature for the two circle methods rises and falls, while the spline method becomes increasingly noisy. For the purpose of model intercomparison, we selected the depth method to calculate radius of curvature.

Figure 5 shows the time evolution of the radius of curvature calculated using the depth method for two models, 18 and 36 , identical in model setup except for the presence of a lower mantle in 18. The radius of curvature for both models is more or less the same during the period of relaxation. At about 5 million years in model time they begin to diverge. The radius of curvature for model 36 , with no lower mantle, rapidly decreases until about 6 million years, when the slab 


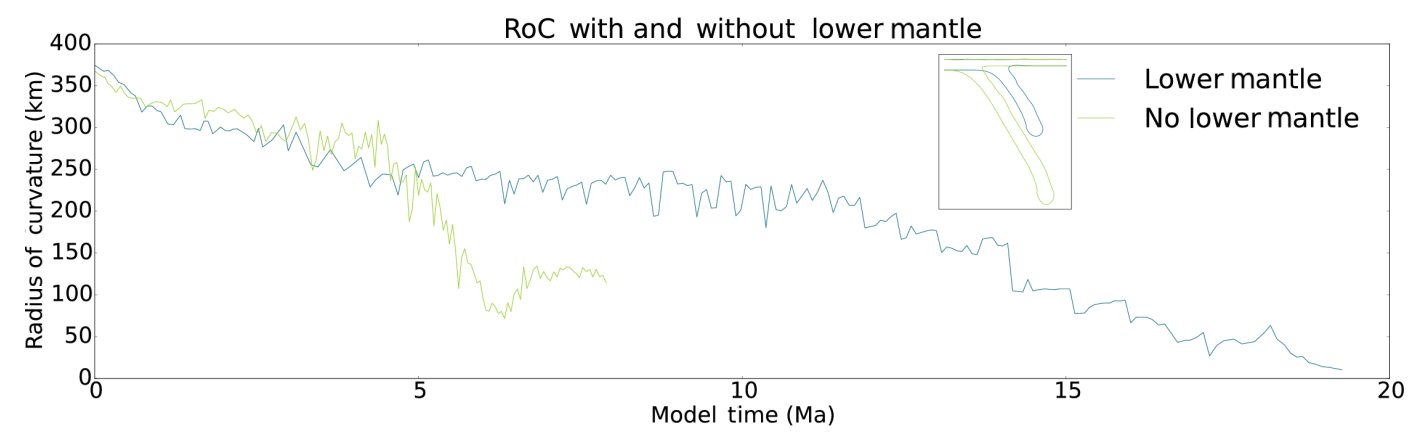

Figure 5. The radius of curvature (RoC) over time for models 18 and 36, each with the same parameters, except for the presence of a lower mantle. The inset shows the $1550 \mathrm{~K}$ isotherm for each of the models at $4.4 \mathrm{Ma}$. The tip of the slab in model 18 (with a lower mantle) has descended to a depth of $625 \mathrm{~km}$, while in the same time the tip of the slab in model 36 (no lower mantle) is at a depth of $1180 \mathrm{~km}$.

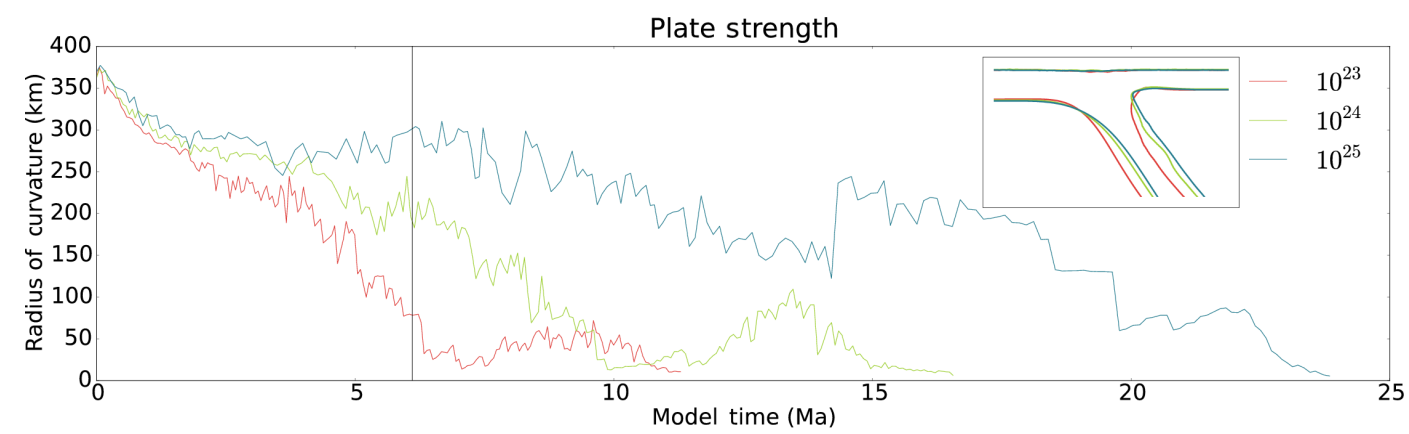

Figure 6. The change in radius of curvature over time for three models of different plate strength, models 11,14 , and 17 . The inset shows the $1550 \mathrm{~K}$ isotherm at the plate interface.

encounters the bottom of the box. The radius of curvature for model 18 continues to decrease at about the same rate.

Figure 6 shows the radius of curvature over time for three models with varying maximum viscosities of the surface plate. The blue (model $17,10^{25} \mathrm{Pas}$ ), green (model $14,10^{24} \mathrm{Pas}$ ), and red (model $11,10^{23} \mathrm{Pas}$ ) plots show the strong, intermediate, and weak plates. The slabs all have the same amount of relative weakening, a maximum slab viscosity of $10 \%$ of the plate viscosity. The inset in the plot shows the $1550 \mathrm{~K}$ isotherm, with the same color scheme as the plot at a model time of 6 million years. The plot shows that weaker plates have a larger rate of radius of curvature reduction. As the radius of curvature changes due to the buckling of the plates $(\sim 7-11$ Ma for model $11, \sim 12-15$ Ma for 14 , and $\sim 16-19 \mathrm{Ma}$ for 17 ), the maximum radius of curvature during that period is highest for the strongest plate, intermediate for the intermediate strength plate, and lowest for the weakest plate.

Figure 7 shows the radius of curvature during model runs for three models with the same plate strength, $10^{24} \mathrm{Pas}$, and differing slab strengths (model $131 \%$, model $1410 \%$, model $15100 \%$ ). In these models, the decrease in the radius of curvature is fastest for the weakest slab models and slowest for the strongest slab model. During the period of buckling, the maximum radius of each models is within $50 \mathrm{~km}$ of each other. The length of this phase is the longest for the weakest slab at almost $10 \mathrm{Ma}$, while for the strongest slab the phase lasts $\sim 3 \mathrm{Ma}$, and for the intermediate slab the phase is about $6 \mathrm{Ma}$.

In Figs. 8 to 11, we compare the varying slab morphologies emergent in models of common plate strength and slab weakening.

Figure 8 compares models with the strongest plate strength tested in this study, plates with a maximum viscosity of $10^{25} \mathrm{Pas}$ and a lithospheric thickness of $80 \mathrm{~km}$. The three models, 16,17 , and 18 , have slab weakening parameters of 1,10 , and $100 \%$, respectively. The two stronger slab models, 17 and 18, penetrate the lower mantle. Model 18 penetrates the deepest and bends, allowing the slab to lay flat at the top of the lower mantle. Model 17 does not penetrate as deep and in laying flat does not bend the portion of the slab which has just entered the mantle. The weakest slab was deflected as it approached the lower mantle and the tip remains in the upper mantle.

A similar comparison of models of equal plate strength and varied slab strength is shown in Fig. 9. In this figure we plot the weakest plates of the model suite. The plates are thinner $(50 \mathrm{~km})$ than those discussed above and have a lower plate maximum viscosity, $10^{23} \mathrm{Pas}$. These plates are easily deflected as they approach the lower mantle and the tips do 


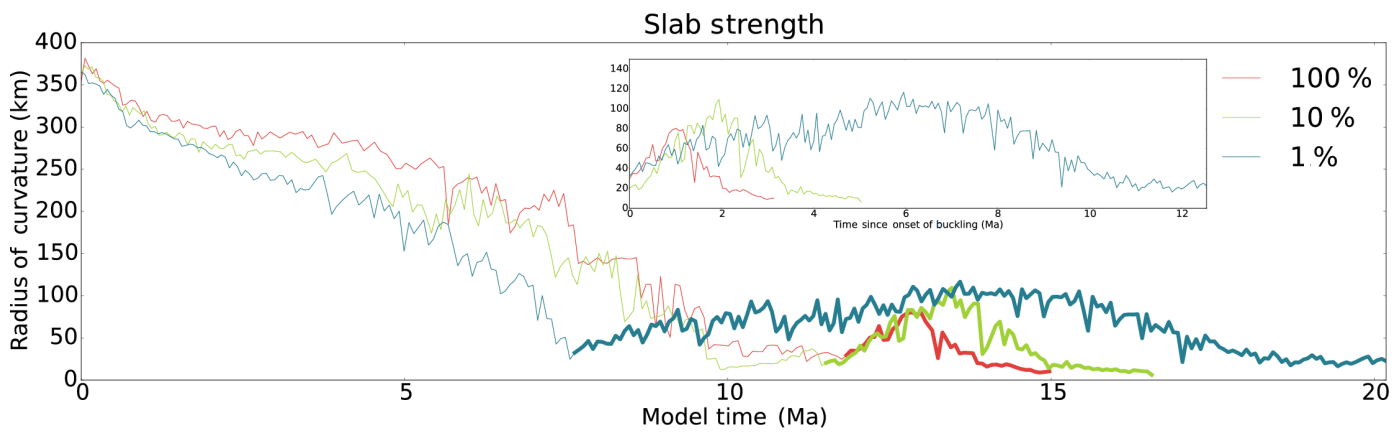

Figure 7. The change in radius of curvature for three models with the same plate strength and three different weakening parameters, models 15,14 , and 13. Bold lines show the period of slab buckling. The inset shows the radius of curvature with the plot shifted to the onset of buckling.

not penetrate. The tips are deflected upward as the following plate descends. The result is a shillelagh-shaped slab tip. Model 3, at the time step shown, has begun the convective style of a two-sided downwelling as the overriding plate is not strong enough to resist the downward forces at the plate interface.

In Figs. 10 and 11 we show comparisons of models with varying plate strength and equal slab strength. Models with $80 \mathrm{~km}$ thick plates, slab maximum viscosity of $10^{23} \mathrm{~Pa} \mathrm{~s}$, and plate viscosities of $10^{23} \mathrm{Pas}$ (model 12), $10^{24} \mathrm{Pas}$ (model 14), and $10^{25} \mathrm{~Pa}$ s (model 16) are shown in Fig. 10. The relatively weak slabs lie at the bottom of the upper mantle and have a similar shape at depth. The shapes of the subducted slabs found in the shallow mantle are differentiated by their radius of curvature. Model 16, with the strongest plate, has the largest radius of curvature, while model 2 , with the weakest plate, has the smallest radius of curvature of the three models.

Figure 11 shows a set of models with weaker surface plates than those shown in Fig. 10. The maximum viscosities of the plates are $10^{23} \mathrm{Pas}$ (model 3), $10^{24} \mathrm{Pas}$ (model 5), and $10^{25} \mathrm{Pas}$ (model 7) but the thickness of the plates has been reduced to $50 \mathrm{~km}$. These models have smaller radii of curvature and the slabs approach the lower mantle at a less acute angle than their $80 \mathrm{~km}$ thick plate counterparts. As such, the tips of the slab in these models are deflected more and, like the models plotted in Fig. 9, take on a shillelagh shape. Here again, we see that the subducting plate of model 3 has begun to pull down the overriding plate.

\section{Discussion}

\subsection{Radius of curvature}

The observed states of models, relaxing from the initial condition, encountering the upper/lower mantle boundary and buckling, are associated with changes to the radius of curvature as calculated by the two circle methods. The spline method for calculating radius of curvature is not sensitive to

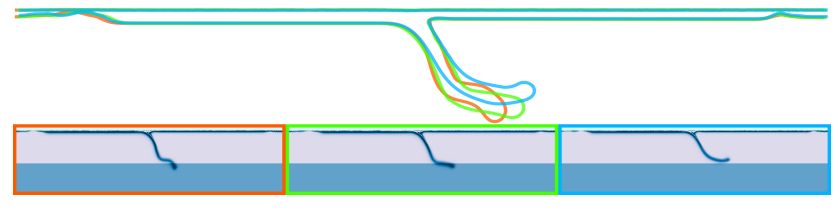

Figure 8. $1550 \mathrm{~K}$ isotherm for models 18 (left/orange), 17 (center/green), and 16 (right/blue). Surface plates are $80 \mathrm{~km}$ thick and have a maximum viscosity of $10^{25} \mathrm{~Pa}$; the slab strength for models 18,17 , and 16 is $10^{25} \mathrm{~Pa} \mathrm{~s}, 10^{24} \mathrm{~Pa}$ s, and $10^{23} \mathrm{~Pa}$ respectively. Subfigures show viscosity for each model.

these states. The depth method captures a greater number of crust particles than the angle method and is consequently less noisy. Noisier still is the spline method. The spline method is subject to an arbitrary smoothing penalty. The minimum radius of curvature is a function of far fewer points than either of the circle methods. The points closest to the point of minimum radius of curvature are fit smoothly and have the largest effect on the radius of curvature, while points at increasing distance have less weight.

Radii of curvature are commonly used to calculate bending dissipation which is balanced against the gravitational potential energy of sinking slabs (Conrad and Hager, 1999; Buffett and Rowley, 2006; Buffett and Heuret, 2011; Holt et al., 2015b). Numerical models have the advantage that the energy of bending dissipation can be calculated within the model, and the slabs are subject to a full set of dynamic forces, which are incorporated therein. Further, observations of earthquakes used to calculate the radius of curvature are limited in number as compared to numerical models which can employ many more tracers to which a particular method can be fit against. Finally, the calculations of radius of curvature are limited to the present day for observations of Earth, whilst models provide a time series of radii of curvature. Studies that use earthquake hypocenter locations (Wu et al., 2008; Buffett and Heuret, 2011) and the spline method likely underestimate the radius of curvature and calculate dissipa- 


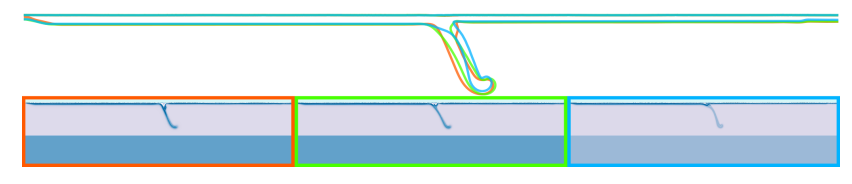

Figure 9. $550 \mathrm{~K}$ isotherm for models 3 (left/orange), 2 (center/green), and 1 (right/blue). Surface plates are $50 \mathrm{~km}$ thick and have a maximum viscosity of $10^{23} \mathrm{~Pa} \mathrm{~s}$; the slab strength for models 3, 2, and 1 is $10^{23} \mathrm{Pas}, 10^{22} \mathrm{Pas}$, and $10^{21} \mathrm{Pas}$ respectively. Subfigures show viscosity for each model.

tion for a single time step, invoking "steady-state" subduction, the appropriateness of which is discussed below.

\subsection{Strong plates}

The steeply dipping slabs apply a stronger torque on the overriding plate than shallow dipping slabs. Experiments, numerical and analog, suggest that tectonic plates are strong, with viscosity contrasts several hundred times that of the mantle (Gerya et al., 2008; Capitanio et al., 2010; Stegman et al., $2010 \mathrm{~b}$, a). In our experiments, strong subducting plates maintain their large radius of curvature for a longer time period than their weaker counterparts. Weaker plates quickly relax from the initial condition. Weak plate models more quickly transition from single-sided subduction to two-sided downwellings. This pathway to two-sided downwellings is discussed at length in Petersen et al. (2015). Models in Petersen et al. (2015) typically had plates with strengths similar to the weakest plates in this study and also explored weaker plates in which the transition to two-sided downwellings occurs almost immediately. Model features like strong plates with a weak coupling at the plate interface, such as a plate boundary fault, suppressed feedback which resulted in two-sided downwellings.

\subsection{Weak slabs}

Numerical models and observation reveal a rich variety of subducted slab morphologies. Computational models may modify plate strength and rheological laws to a variety of subduction styles (Stegman et al., 2010b, a; Garel et al., 2014; Petersen et al., 2015). Subducted slabs may pile at the upper/lower mantle boundary, as suggested of the Australian plate below Java and the Cocos plate below Central America, (Ribe et al., 2007), may penetrate in the lower mantle (Zhong and Gurnis, 1995), and may lie flat along the boundary (Fukao et al., 2001). While tomographic evidence does not reveal the interior structure of observed piles, Ribe et al. (2007) assert that observed structures are "too large to be easily explained by a mechanism other than buckling."

Other work has suggested that slabs stalled at the upper/lower mantle boundary may eventually "avalanche" into the lower mantle (Stein and Hofmann, 1994; Breuer and Spohn, 1995; Condie, 1995). The models of this paper with

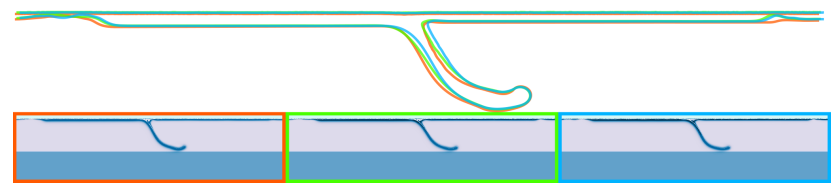

Figure 10. $1550 \mathrm{~K}$ isotherm for models 12 (left/orange), 14 (center/green), and 16 (right/blue). Surface plates are $80 \mathrm{~km}$ thick and have a maximum viscosity of $10^{23} \mathrm{~Pa} \mathrm{~s}, 10^{24} \mathrm{~Pa} \mathrm{~s}$, and $10^{25} \mathrm{~Pa}$ s for models 12,14 , and 16 respectively. Slabs have a maximum viscosity of $10^{23} \mathrm{~Pa}$. Subfigures show viscosity for each model.

strong plates and strong slabs result in some models where the slab tip is embedded into the lower mantle as the slab descends through the upper mantle. Once embedded there is no lateral motion of the subducted slab and it begins to buckle. The stresses are transmitted to the surface and modify the radius of curvature over a short period of time. The very weakest slabs do not immediately penetrate into the lower mantle; rather they rest on the boundary. Weaker slabs exhibit piling and flat-lying slabs, and represent the most analogous behavior in regard to the range of observed slab morphologies in Earth. The stresses that bend the subducted slab to pile it are weaker and do not modify the radius of curvature as rapidly. Eventually these slabs do descend into the lower mantle.

In this study the weakening mechanism is active at a depth below the base of the surface plates. The range of weakening was selected so that we could explore the effects of reduced viscosity on the subducted lithosphere. Work done by Garel et al. (2014) evaluated the dominant deformation mechanisms at work in subduction settings. That study found that the subducted slab was subject to both Peierls creep and dislocation creep below the base of the surface plates, i.e., in the same area where the models of this study apply the weakening mechanism. The depth at which we begin to apply our weakening mechanism corresponds to the depth at which the slab has descended past the bending region. In our models it is in the bending region that the yield criteria are exceeded. Below the bending region the stress does not exceed the yield criteria and the material is assigned a purely temperaturedependent viscosity, without regard to its history of yielding. The limiting of the maximum viscosity below the bending region has the effect of lowering the mesoscale strength of the plate as a proxy for weakening due to the development of non-resolvable faults and/or by grain size effects of damage rheology.

Though the weakening mechanism is turned on at these shallow depths, the morphology of the slab in the shallow upper mantle appears to be firstly controlled by the strength of the surface plate and is not sensitive to the weakening of the slab. This is best demonstrated in Figs. 8 and 10. Figure 8 shows three models at the same model time. In these models the plates have the same thickness and maximum viscosity and are of the same strength. The slab weakening parameters are, however, different for each. Model 18 (orange) has a 


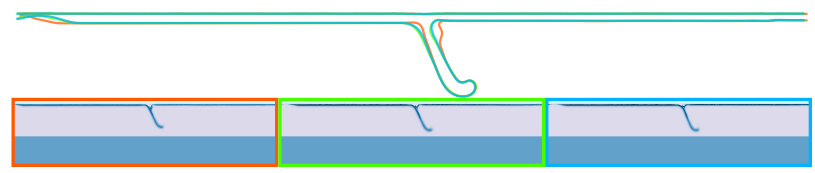

Figure 11. $1550 \mathrm{~K}$ isotherm for models 3 (left/orange), 5 (center/green), and 7 (right/blue). Surface plates are $50 \mathrm{~km}$ thick and have a maximum viscosity of $10^{23} \mathrm{~Pa} \mathrm{~s}, 10^{24} \mathrm{~Pa} \mathrm{~s}$, and $10^{25} \mathrm{~Pa}$ s for models 3, 5, and 7 respectively. Slabs have a maximum viscosity of $10^{23}$ Pa s. Subfigures show viscosity for each model.

maximum viscosity of $10^{25} \mathrm{Pas}$, with no weakening, model 17 (green) has a maximum viscosity of $10^{24}$, with weakening to $10 \%$ of the plate, and model 16 (blue) has a maximum viscosity of $10^{23}$, with weakening to $1 \%$ of the plate. The overlapping contours, the isotherm at $1550 \mathrm{~K}$, of the figure show the slab shape. At depth the slab morphologies are extremely different, while the slab morphology in the shallow upper mantle is substantially the same. This is in contrast to the shape of slabs shown in Fig. 10. In that figure, the models shown have differing plate strengths: model 12 (orange) has a maximum viscosity of $10^{23} \mathrm{~Pa} \mathrm{~s}$, model 14 (green) $10^{24} \mathrm{~Pa} \mathrm{~s}$, and model 16 (blue) $10^{25} \mathrm{~Pa}$ s. The slab strength of all models is the same, $10^{23} \mathrm{~Pa}$ s. In this set of models, the overlapping slab contours show that the slab shapes at depth are similar, while the shapes of the slab in the shallow upper mantle differ. This is evidence that the strength of the hinge is just as important to the overall evolution of the slab than the strength of the slab itself.

\subsection{No lower mantle}

The effects of a lower mantle on subduction and the extent to which the lower mantle participates in convection are debated on both geophysical and geochemical grounds (Davies, 1977; Loper, 1985; van Keken and Ballentine, 1998; Tackley, 2000; Stegman et al., 2002). In this study we constructed models with a lower mantle and without, both of which had the same vertical extent. Our models find that the absence of a lower mantle has the effect of speeding up subduction due to the higher Ra as compared to models with a lower mantle. The lower boundary of the model has a no-slip boundary condition. As such, strong plates behave similarly to when the lower mantle is present, i.e., the horizontal motion of the slab is stopped. For weak slabs that lie upon the lower mantle, the horizontal motion is diminished, but not entirely stopped, due to traction at the upper/lower mantle boundary. In models with no lower mantle, the cessation of horizontal motion is more complete and immediate, owing to the no-slip boundary condition.

\subsection{Steady-state subduction}

The concept of steady-state subduction as invoked in scientific literature is variously defined depending on the context of a particular paper. Articles that examine earthquake cycles consider the long-term motion of the plates to be steady-state as compared to the stick and slip of earthquakes that take place on timescales of decades or centuries (Savage, 1983; Fukahata et al., 1996; Wang et al., 2012). Studies that examine the state of subduction zones in terms of heat (Molnar and England, 1995; Currie, 2004), deformation (Sato and Matsu'ura, 1988; Fukahata et al., 1996; Wang et al., 2012), or asthenosphere flow (Funiciello et al., 2006) exclude the deeper mantle and interaction of the subducted slab and the lower mantle. Further instantaneous single time step models are necessarily steady-state. Several studies, including this one, suggest that subduction on geologic timescales is not steady-state. Models that assimilate realistic plate history including changing plate velocities and plate boundaries generate slab morphologies that are comparable to tomographic observations (Liu and Stegman, 2011). The analog models of Guillaume et al. (2009) result in systems with dynamic trench migration and "never [reach] any steady-state regime", with the dip angle oscillating between steepening and flattening at the surface as the slab buckles and folds at the bottom of the upper mantle. Zhong and Gurnis (1995) subduction models exhibit non-steady-state changes to plate velocity as subducted slabs entered the lower mantle. In work by Stegman et al. (2006) and Bellahsen (2005), steady state is referred to in the context of a steady-state phase. In this study we find that the state of the subduction zone changes throughout the span of the experiment. The primary metric of radius of curvature, we note, is firstly noisy throughout the model run. This is true for any method used to calculate the radius of curvature. For our preferred method, fitting a circle to $150 \mathrm{~km}$, the change in radius of curvature exceeds the noise and captures salient behavior as the model evolves. Work by Capitanio et al. (2009) finds that curvature is modified to minimize bending dissipation. In the models of this study, a decrease in radius of curvature is associated with the relaxation from the initial condition and the descent of the slab through the upper mantle. An increase in the rate of radius reduction begins as the slab encounters the lower mantle and continues as the slab lies upon the upper/lower mantle boundary. The radius of curvature increases and decreases in a manner similar to Guillaume et al. (2009) during slab buckling.

\section{Conclusions}

Our evaluation of three methods for calculating radius of curvature showed that its time-varying nature is related to the state of the subducted slab. The spline method is subject to variability in models due to its nature and selection of a smoothing parameter. The spline method results in a smaller 
radius of curvature than either of the two circle methods. The circle methods are sensitive to changes of the morphology of the subducted slab, while the spline method is not. The method of fitting a circle to slab shape from the surface to a depth of $150 \mathrm{~km}$ is sensitive to the state of the subducted slab below $150 \mathrm{~km}$, covers a wide range of radii of curvature, and is less noisy than other methods.

The strength of plates and slabs independently controls the shape of the shallow slab and subducted slab. The richness of slab morphology as seen in tomographic inversions suggests that the mechanical strength of tectonic plates is modified by some mechanism. As in Petersen et al. (2015), we find that surface plates transition from single-sided mode is too weak and occurs early in the model evolution. That study also found that plates that are too strong cannot be bent and subducted, resulting in the system evolving into the stagnantlid regime.

Strong plates resist bending and preserve larger radii of curvature. Smaller radii of curvature, the result of vertical descending or steeply dipping slabs, promote two-sided convection. Larger radii of curvature preserve single-sided subduction. At depth, strong slabs embed in the lower mantle, transmit bending stresses to the surface, and decrease radii of curvature. Weak slabs at depth are less coupled to the lower mantle, and inhibit the transmission of stress to the surface.

Earth-like subduction is single-sided and supports a wide range of radii of curvature and slab morphologies. In this study, the richness of such observations is best reproduced by a combination of strong surface plates and weakened slabs. The strong plates promote single-sided subduction while the weakened slabs allow slabs to bend, pile, or lie flat, as is seen in tomographic inversions.

Acknowledgements. We are grateful to Boris Kaus and an anonymous reviewer for their constructive comments. This material is based upon work supported by the National Science Foundation under grant no. 1255040. This work used the Extreme Science and Engineering Discovery Environment (XSEDE), which is supported by the National Science Foundation grant number ACI-1053575. The authors acknowledge the Texas Advanced Computing Center (TACC) at the University of Texas at Austin for providing HPC resources that have contributed to the research results reported within this paper.

Edited by: J. C. Afonso

Reviewed by: B. J. P. Kaus and one anonymous referee

\section{References}

Becker, T. W., Faccenna, C., O'Connell, R. J., and Giardini, D.: The development of slabs in the upper mantle: Insights from numerical and laboratory experiments, J. Geophys. Res., 104, 15207, doi:10.1029/1999JB900140, 1999.
Bellahsen, N.: Dynamics of subduction and plate motion in laboratory experiments: Insights into the "plate tectonics" behavior of the Earth, J. Geophys. Res., 110, B10401, doi:10.1029/2004JB002999, 2005.

Bercovici, D.: The generation of plate tectonics from mantle convection, Earth Planet. Sc. Lett., 205, 107-121, doi:10.1016/S0012-821X(02)01009-9, 2003.

Bercovici, D., Schubert, G., and Ricard, Y.: Abrupt tectonics and rapid slab detachment with grain damage, P. Natl. Acad. Sci. USA, 112, 1287-1291, doi:10.1073/pnas.1415473112, 2015.

Breuer, D. and Spohn, T.: Possible flush instability in mantle convection at the Archaean-Proterozoic transition, Nature, 378, 608610, doi:10.1038/378608a0, 1995.

Buffett, B. A. and Heuret, A.: Curvature of subducted lithosphere from earthquake locations in the Wadati-Benioff zone, Geochem. Geophy. Geosy., 12, Q06010, doi:10.1029/2011GC003570, 2011.

Buffett, B. A. and Rowley, D.: Plate bending at subduction zones: Consequences for the direction of plate motions, Earth Planet. Sc. Lett., 245, 359-364, doi:10.1016/j.epsl.2006.03.011, 2006.

Capitanio, F. A., Morra, G., and Goes, S.: Dynamics of plate bending at the trench and slab-plate coupling, Geochem. Geophy. Geosy., 10, Q04002, doi:10.1029/2008GC002348, 2009.

Capitanio, F. A., Stegman, D. R., Moresi, L., and Sharples, W.: Upper plate controls on deep subduction, trench migrations and deformations at convergent margins, Tectonophysics, 483, 80-92, doi:10.1016/j.tecto.2009.08.020, 2010.

Clark, S. R., Stegman, D., and Müller, R. D.: Episodicity in backarc tectonic regimes, Phys. Earth Planet. In., 171, 265-279, doi:10.1016/j.pepi.2008.04.012, 2008.

Condie, K. C.: Episodic ages of Greenstones: A key to mantle dynamics?, Geophys. Res. Lett., 22, 2215-2218, doi:10.1029/95GL01804, 1995.

Conrad, C. P. and Hager, B. H.: Effects of plate bending and fault strength at subduction zones on plate dynamics, J. Geophys. Res., 104, 17551, doi:10.1029/1999JB900149, 1999.

Crameri, F., Schmeling, H., Golabek, G. J., Duretz, T., Orendt, R., Buiter, S. J. H., May, D. A., Kaus, B. J., Gerya, T. V., and Tackley, P. J.: A comparison of numerical surface topography calculations in geodynamic modelling: an evaluation of the "sticky air" method, Geophys. J. Int., 189, 38-54, doi:10.1111/j.1365246X.2012.05388.x, 2012a.

Crameri, F., Tackley, P. J., Meilick, I., Gerya, T. V., and Kaus, B. J.: A free plate surface and weak oceanic crust produce singlesided subduction on Earth, Geophys. Res. Lett., 39, L03306, doi:10.1029/2011GL050046, 2012b.

Currie, C. A.: The thermal effects of steady-state slab-driven mantle flow above a subducting plate: the Cascadia subduction zone and backarc, Earth Planet. Sc. Lett., 223, 35-48, doi:10.1016/j.eps1.2004.04.020, 2004.

Davies, G. F.: Whole-mantle convection and plate tectonics, Geophys. J. Int., 49, 459-486, doi:10.1111/j.1365246X.1977.tb03717.x, 1977.

De Boor, C.: A Practical Guide to Splines, no. v. 27 in Applied Mathematical Sciences, Springer-Verlag, 1978.

Fukahata, Y., Honsho, C., and Matsu'ura, M.: Crustal movements on Shikoku, southwestern Japan, inferred from inversion analysis of levelling data using ABIC, Tectonophysics, 257, 239-252, doi:10.1016/0040-1951(95)00176-X, 1996. 
Fukao, Y., Widiyantoro, S., and Obayashi, M.: Stagnant slabs in the upper and lower mantle transition region, Rev. Geophys., 39, 291-323, doi:10.1029/1999RG000068, 2001.

Funiciello, F., Moroni, M., Piromallo, C., Faccenna, C., Cenedese, A., and Bui, H. A.: Mapping mantle flow during retreating subduction: Laboratory models analyzed by feature tracking, J. Geophys. Res., 111, B03402, doi:10.1029/2005JB003792, 2006.

Garel, F., Goes, S., Davies, D. R., Davies, J. H., Kramer, S. C., and Wilson, C. R.: Interaction of subducted slabs with the mantle transition-zone: A regime diagram from 2-D thermo-mechanical models with a mobile trench and an overriding plate, Geochem. Geophy. Geosy., 15, 1739-1765, doi:10.1002/2014GC005257, 2014.

Gerya, T. V., Connolly, J. A., and Yuen, D. A.: Why is terrestrial subduction one-sided?, Geology, 36, 43-46, doi:10.1130/G24060A.1, 2008.

Guillaume, B., Martinod, J., and Espurt, N.: Variations of slab dip and overriding plate tectonics during subduction: Insights from analogue modelling, Tectonophysics, 463, 167-174, doi:10.1016/j.tecto.2008.09.043, 2009.

Holt, A. F., Becker, T. W., and Buffett, B. A.: Trench migration and overriding plate stress in dynamic subduction models, Geophys. J. Int., 201, 172-192, doi:10.1093/gji/ggv011, 2015a.

Holt, A. F., Buffett, B. A., and Becker, T. W.: Overriding plate thickness control on subducting plate curvature, Geophys. Res. Lett., 42, 3802-3810, doi:10.1002/2015GL063834, 2015 b.

Jarrard, R. D.: Relations among subduction parameters, Rev. Geophys., 24, 217-284, doi:10.1029/RG024i002p00217, 1986.

Kameyama, M., Yuen, D. A., and Karato, S.-I.: Thermalmechanical effects of low-temperature plasticity (the Peierls mechanism) on the deformation of a viscoelastic shear zone, Earth Planet. Sc. Lett., 168, 159-172, doi:10.1016/S0012821X(99)00040-0, 1999.

Lenardic, A. and Crowley, J. W.: On the notion of well-defined tectonic regimes for terrestrial planets in this solar system and others,Astrophys. J., 755, 132-143, doi:10.1088/0004637X/755/2/132, 2012.

Liu, L. and Stegman, D. R.: Segmentation of the Farallon slab, Earth Planet. Sc. Lett., 311, 1-10, doi:10.1016/j.eps1.2011.09.027, 2011.

Loper, D. E.: A simple model of whole-mantle convection, J. Geophys. Res., 90, 1809, doi:10.1029/JB090iB02p01809, 1985.

Molnar, P. and England, P.: Temperatures in zones of steady-state underthrusting of young oceanic lithosphere, Earth Planet. Sc. Lett., 131, 57-70, doi:10.1016/0012-821X(94)00253-U, 1995.

O'Neill, C. J.: Tectonothermal evolution of solid bodies: terrestrial planets, exoplanets and moons, Aust. J. Earth Sci., 59, 189-198, doi:10.1080/08120099.2012.644403, 2012.

O'Rourke, J. G. and Korenaga, J.: Terrestrial planet evolution in the stagnant-lid regime: Size effects and the formation of self-destabilizing crust, Icarus, 221, 1043-1060, doi:10.1016/j.icarus.2012.10.015, 2012.

Petersen, R. I., Stegman, D. R., and Tackley, P. J.: A regime diagram of mobile lid convection with plate-like behavior, Phys. Earth Planet. In., 241, 65-76, doi:10.1016/j.pepi.2015.01.002, 2015.

Ribe, N., Stutzmann, E., Ren, Y., and van der Hilst, R.: Buckling instabilities of subducted lithosphere beneath the transition zone, Earth Planet. Sc. Lett., 254, 173-179, doi:10.1016/j.epsl.2006.11.028, 2007.
Royden, L. H. and Husson, L.: Subduction Zone Geodynamics, chap. Subduction with Variations in Slab Buoyancy: Models and Application to the Banda and Apennine Systems, 35-45, Springer Berlin Heidelberg, Berlin, Heidelberg, doi:10.1007/978-3-540-87974-9_2, 2009.

Sato, T. and Matsu'ura, M.: A kinematic model for deformation of the lithosphere at subduction zones, J. Geophys. Res., 93, 6410, doi:10.1029/JB093iB06p06410, 1988.

Savage, J. C.: A dislocation model of strain accumulation and release at a subduction zone, J. Geophys. Res., 88, 4984-4996, doi:10.1029/JB088iB06p04984, 1983.

Schmeling, H., Babeyko, A., Enns, A., Faccenna, C., Funiciello, F., Gerya, T. V., Golabek, G. J., Grigull, S., Kaus, B. J., Morra, G., Schmalholz, S., and van Hunen, J.: A benchmark comparison of spontaneous subduction models-Towards a free surface, Phys. Earth Planet. In., 171, 198-223, doi:10.1016/j.pepi.2008.06.028, 2008.

Solomatov, V. and Moresi, L.: Three regimes of mantle convection with non-Newtonian viscosity and stagnant lid convection on the terrestrial planets, Geophys. Res. Lett., 24, 1907-1910, doi:10.1029/97GL01682, 1997.

Stegman, D. R., Richards, M. A., and Baumgardner, J. R.: Effects of depth-dependent viscosity and plate motions on maintaining a relatively uniform mid-ocean ridge basalt reservoir in whole mantle flow, J. Geophys. Res., 107, ETG 5-1-ETG 5-8, doi:10.1029/2001JB000192, 2002.

Stegman, D. R., Freeman, J., Schellart, W. P., Moresi, L., and May, D.: Influence of trench width on subduction hinge retreat rates in 3-D models of slab rollback, Geochem. Geophy. Geosy., 7, Q03012, doi:10.1029/2005GC001056, 2006.

Stegman, D. R., Farrington, R., Capitanio, F. A., and Schellart, W.: A regime diagram for subduction styles from 3-D numerical models of free subduction, Tectonophysics, 483, 29-45, doi:10.1016/j.tecto.2009.08.041, 2010a.

Stegman, D. R., Schellart, W., and Freeman, J.: Competing influences of plate width and far-field boundary conditions on trench migration and morphology of subducted slabs in the upper mantle, Tectonophysics, 483, 46-57, doi:10.1016/j.tecto.2009.08.026, 2010b.

Stein, M. and Hofmann, A. W.: Mantle plumes and episodic crustal growth, Nature, 372, 63-68, doi:10.1038/372063a0, 1994.

Tackley, P. J.: Mantle Convection and Plate Tectonics: Toward an Integrated Physical and Chemical Theory, Science, 288, 2002 2007, doi:10.1126/science.288.5473.2002, 2000.

Tackley, P. J.: Modelling compressible mantle convection with large viscosity contrasts in a three-dimensional spherical shell using the yin-yang grid, Phys. Earth Planet. In., 171, 7-18, doi:10.1016/j.pepi.2008.08.005, 2008.

van Keken, P. E. and Ballentine, C.: Whole-mantle versus layered mantle convection and the role of a high-viscosity lower mantle in terrestrial volatile evolution, Earth Planet. Sc. Lett., 156, 1932, doi:10.1016/S0012-821X(98)00023-5, 1998.

Wang, K., Hu, Y., and He, J.: Deformation cycles of subduction earthquakes in a viscoelastic Earth, Nature, 484, 327-332, doi:10.1038/nature11032, 2012. 
Wu, B., Conrad, C. P., Heuret, A., Lithgow-Bertelloni, C., and Lallemand, S.: Reconciling strong slab pull and weak plate bending: The plate motion constraint on the strength of mantle slabs, Earth Planet. Sc. Lett., 272, 412-421, doi:10.1016/j.epsl.2008.05.009, 2008.
Zhong, S. and Gurnis, M.: Mantle Convection with Plates and Mobile, Faulted Plate Margins, Science, 267, 838-843, doi:10.1126/science.267.5199.838, 1995. 